\title{
Coupled Fluids-Radiation Analysis of a High-Mass Mars Entry Vehicle
}

\author{
Grant Palmer*, Gary Allen+ \\ ERC Incorporated, Huntsville, AL 35805 \\ Chun Tang ${ }^{\perp}$, Jim Brown ${ }^{\perp}$ \\ NASA Ames Research Center, Moffett Field, CA 94035
}

\begin{abstract}
The NEQAIR line-by-line radiation code has been incorporated into the DPLR Navier-Stokes flow solver such that the NEQAIR subroutines are now callable functions of DPLR. The coupled DPLR-NEQAIR code was applied to compute the convective and radiative heating rates over high-mass Mars entry vehicles. Two vehicle geometries were considered - a $15 \mathrm{~m}$ diameter 70-degree sphere cone configuration and a slender, mid-L/D vehicle with a diameter of $5 \mathrm{~m}$ called an Ellipsled. The entry masses ranged from 100 to 165 metric tons. Solutions were generated for entry velocities ranging from 6.5 to $9.1 \mathrm{~km} / \mathrm{s}$. The coupled fluids-radiation solutions were performed at the peak heating location along trajectories generated by the Traj trajectory analysis code. The impact of fluids-radiation coupling is a function of the level of radiative heating and the freestream density and velocity. For the high-mass Mars vehicles examined in this study, coupling effects were greatest for entry velocities above $8.5 \mathrm{~km} / \mathrm{s}$ where the surface radiative heating was reduced by up $\mathbf{1 7 \%}$. Generally speaking, the Ellipsled geometry experiences a lower peak radiative heating rate but a higher peak turbulent convective heating rate than the MSL-based vehicle.
\end{abstract}

\section{$\underline{\text { Nomenclature }}$}

$\alpha_{n} \quad=$ volumetric absorption coefficient, $1 / \mathrm{cm}$

B $\quad=$ effective or piecewise blackbody spectrum, $\mathrm{W} / \mathrm{cm}^{2}-\mu \mathrm{m}-\mathrm{sr}$

$\mathrm{E}=$ spontaneous emission intensity, W/ $\mathrm{cm}^{3}-\mathrm{sr}$

e $\quad=$ total energy, $\mathrm{J} / \mathrm{m}^{3}$

$\mathrm{h} \quad=$ enthalpy, $\mathrm{J} / \mathrm{m}^{3}$

$\mathrm{I}_{\lambda} \quad=$ spectral radiative intensity, $\mathrm{W} / \mathrm{cm}^{2}-\mu \mathrm{m}-\mathrm{sr}$

$\lambda=$ wavelength, angstroms or $\mu \mathrm{m}$

$\mathrm{N}_{\mathrm{L}} \quad=$ population of a non-degenerate lower energy level, $1 / \mathrm{cm}^{3}$

$\mathrm{q}=$ surface heating rate, $\mathrm{W} / \mathrm{m}^{2}$ or $\mathrm{W} / \mathrm{cm}^{2}$

$\mathrm{T}=$ translational temperature, $\mathrm{K}$

$\mathrm{t} \quad=$ time, $\mathrm{s}$

$\tau \quad=$ shear stress, $\mathrm{N} / \mathrm{m}^{2}$

$\mathrm{u} \quad=$ velocity, $\mathrm{m} / \mathrm{s}$

$\Theta^{\mathrm{R}} \quad=$ radiant energy source term, $\mathrm{W} / \mathrm{cm}^{3}$

Superscripts

$\mathrm{R}=$ radiative

Subscripts

ad = adiabatic

coup = coupled

e $\quad=$ electronic

$\mathrm{r} \quad=$ radiative

$\mathrm{v} \quad=$ vibrational

$\mathrm{w} \quad=$ wall

$\infty \quad=$ freestream

Senior Research Scientist, ERC Inc. Senior Member AIAA

Research Scientist, NASA Ames Research Center, Associate Fellow, AIAA 


\section{Introduction}

Since the mid-1970's there have been a number of successful unmanned robotic missions to Mars including the Viking, Pathfinder and MER missions [1]. The capsules for these missions were all based on 70-degree sphere cone geometries with diameters ranging from 2.65 to $3.5 \mathrm{~m}$. The highest entry velocity was achieved by the Mars Pathfinder vehicle at $7.26 \mathrm{~km} / \mathrm{s}$. The proposed Mars Science Laboratory (MSL) mission, currently scheduled to land on Mars in 2012, is the largest unmanned Mars robotic vehicle currently planned and features a $4.5 \mathrm{~m}$ diameter 70-degree sphere cone capsule [2]. The MSL will have an entry velocity in the range of $6.0 \mathrm{~km} / \mathrm{s}$.

In recent years, a number of studies have been performed to determine the vehicle and mission requirements that would enable the human exploration of Mars [1-8]. The vehicle geometries of these proposed high-mass Mars vehicles were based on 70-degree sphere cones, Apollo-type capsules, or a slender, mid lift-over-drag ratio (L/D) vehicle referred to as an Ellipsled. High-mass Mars vehicles would be significantly larger than the unmanned robotic spacecraft due to the requirement of carrying both astronauts and the larger payloads the astronauts would need to live on the surface of Mars. High-mass Mars vehicles would likely have diameters of 10-15 m and might have entry mass values as high as 80-100 metric tons [1].

Human missions to Mars would need to minimize (or at the very least reduce) the transit time from Earth to Mars to reduce the exposure of the astronauts to cosmic radiation [4]. A reduced transit time mission implies a higher entry velocity into the Martian atmosphere than that experienced by unmanned robotic missions. Higher entry velocities result in higher convective and radiative heating rates, and an accurate assessment of the heating rates and the total integrated heat load is required for thermal protection system (TPS) design. A fair amount of system-level analysis has been performed on high-mass Mars vehicles in Refs. [1]-[8], but to date there has been little detailed analysis of the aerothermal loads a high-mass Mars vehicle will experience while entering the Martian atmosphere. Steinfeldt et al. [5] show convective heating rate results generated by the engineering-level tool CBAERO over both the 70-degree sphere cone and mid-L/D vehicles at one trajectory point. Garcia et al. [8] presented both CBAERO and computational fluid dynamic (CFD) convective heating rate solutions over mid-L/D vehicles at the peak heating point of a $7.36 \mathrm{~km} / \mathrm{s}$ entry velocity trajectory. Isolated CBAERO and CFD solutions are shown in Ref. [3] without much description. No attempt was made in Refs. [3], [5], or [8] to calculate the level of radiative heating on the vehicle surface.

The purpose of this paper is to present a detailed analysis of the convective and radiative heating rate environments experienced by both 70-degree sphere cone and mid-L/D high-mass Mars entry vehicles over a range of entry velocities. The heating rates will be computed using a coupled Navier-Stokes CFD and line-by-line radiation code. The effects of fluidradiation coupling will be included in the analysis. This work is being performed as an element of the Models and Analysis Tools (MAT) Element of NASA's Exploration Systems Mission Directorate Entry, Descent, and Landing (EDL) project.

\section{Geometries}

Two high-mass Mars entry vehicle geometries were analyzed in this study. The first geometry considered was a scaled-up version of the Mars Science Laboratory vehicle shown in Fig. 1. The MSL heatshield geometry is a 70-degree sphere cone, a shape that was used in the Viking, Pathfinder, and MERS robotic landers [1]. The MSL vehicle diameter is $4.5 \mathrm{~m}$. For this study, the MSL heatshield shape was used but the diameter was scaled-up to $15 \mathrm{~m}$ to account for the larger size and payload that will be required for human-class high-mass Mars missions. High-mass Mars versions of 70-degree sphere cone geometries were previously studied by Braun and Manning [1], Steinfeldt et al. [5], and Christian et al. [6]. Nominal entry mass values of 100 and 160 metric tons were considered. The estimated payload mass fractions for a $15 \mathrm{~m}$ diameter $70-$ degree sphere cone with nominal lift-over-drag ratio (L/D) of 0.3 is 0.25 [6] meaning that a $15 \mathrm{~m}$ vehicle could land payloads of 25 to 40 metric tons on the surface of Mars. 


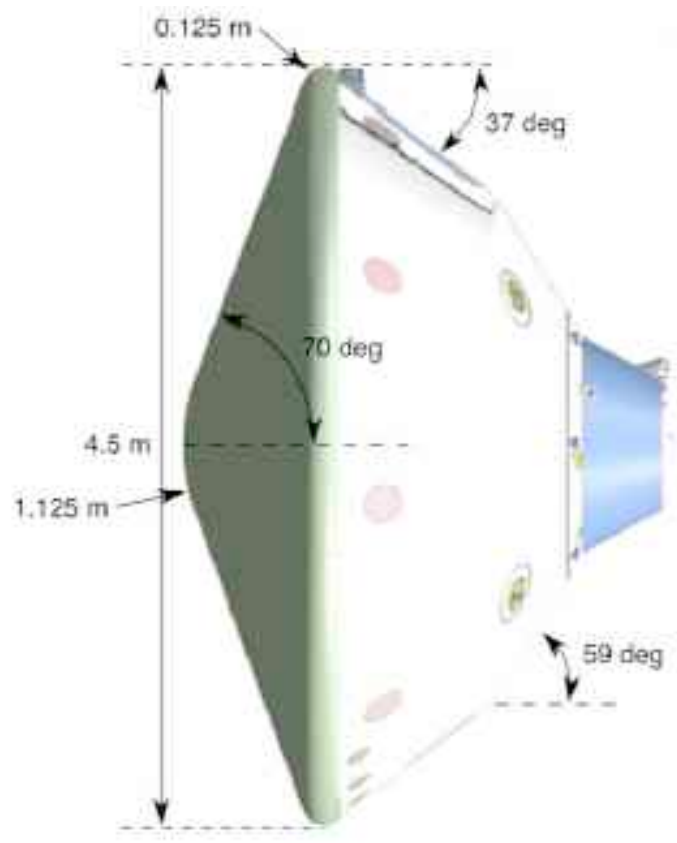

Figure 1. MSL vehicle geometry.

The second vehicle geometry considered in this study was a slender, mid-L/D vehicle also known as the Ellipsled. In its simplest form, as shown in Fig. 2., the Ellipsled consists of a $5 \mathrm{~m}$ radius hemispherical cap placed on a $10 \mathrm{~m}$ diameter cylinder. The overall length of the Ellipsled is $30 \mathrm{~m}$. The 10x30 Ellipsled was previously analyzed by Steinfeldt et al. [5], Garcia et al. [8], Dwyer-Cianciolo et al. [3], and Engelund et al. [7]. The nominal L/D for the Ellipsled was 0.5. Nominal vehicle entry masses of 110 and 165 metric tons were considered. Both Engelund et al. [7] and Garcia et al. [8] suggest that an Ellipsled with a 110-115 metric ton entry mass could land a 40 metric ton payload on the surface of Mars. For this study both a 10x30 Ellipsled with a nominal entry mass of 110 metric tons and a larger 12x35 Ellipsled with an entry mass of 160 metric tons were analyzed.

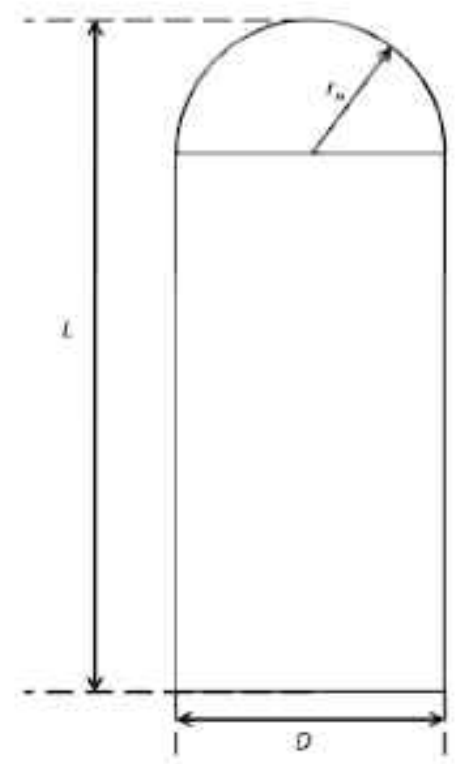

Figure 2. Ellipsled geometry

Both the 70-degree sphere cone and mid-L/D Ellipsled geometries were considered in this study because there is some disagreement in the literature as to which shape is more suitable for crewed high-mass Mars missions. Braun and Manning [1] suggest that the 70-degree sphere cone shape offers a high hypersonic drag coefficient, which can give the vehicle 
sufficient altitude at Mach 3 or 4 to perform the necessary descent and landing procedures for entry masses of 80-120 metric tons. On the other hand, Steinfeldt et al. [5] state that the physical size of the Ellipsled may be useful in accommodating large-volume payloads.

\section{DPLR Overview}

The Data-Parallel Line Relaxation (DPLR) code [9] is a 3-D nonequilibrium Navier-Stokes flow solver used to compute the flow around the high-mass Mars vehicles studied in this paper. DPLR uses a modified Steger-Warming flux-splitting scheme [10], which allows higher-order differencing of the inviscid fluxes without the excess dissipation present with standard Steger-Warming flux splitting. DPLR uses a line-relaxation implicit technique that greatly accelerates solution convergence and is directly portable to massively parallel computer architectures. The DPLR flow solver has been validated over a wide spectrum of flight and ground-based experimental simulations, a small sample of which can be found in Refs. [11 - 16]. DPLR has also been previously applied to analyze the heating rates experienced by Mars entry vehicles both on the heatshield [17-18] and afterbody [19].

For the CFD solutions generated over the high-mass Mars vehicles analyzed in this work, a 16-species Mars gas model was used with species $\left[\mathrm{CO}_{2}, \mathrm{CO}, \mathrm{CO}+, \mathrm{C}_{2}, \mathrm{~N}_{2}, \mathrm{NO}, \mathrm{NO}+, \mathrm{CN}, \mathrm{C}, \mathrm{C}+, \mathrm{N}, \mathrm{O}, \mathrm{O}+, \mathrm{Ar}\right.$, e-]. The Park 1994 reaction rates were considered [20]. Two-temperature ( $\mathrm{T}$ and $\mathrm{Tv}$ ) thermochemical nonequilibrium was modeled. The electronic temperature was assumed to be in equilibrium with the translational temperature. Due to the size of the high-mass Mars entry vehicles, an early transition to turbulent flow is expected [8]. At the peak heating point, where the CFD solutions were computed, the flow was assumed to be fully turbulent over the heatshield. The Baldwin-Lomax turbulence model was used [21]. The surface of the vehicle was modeled using a fully-catalytic, radiative equilibrium wall boundary condition with a constant emissivity, $\varepsilon=0.85$.

The uncertainty of convective heating rates predicted by DPLR for Mars gas mixtures due to uncertainties in modeling parameters (collision integral cross sections, chemical reaction rates, etc.) was estimated by Bose et al. [22] to range between $11-13 \%$ for a 70 -degree sphere cone heatshield. Convective heating rates predicted by DPLR in a $\mathrm{CO}_{2}$ gas mixture over a scale model of the MSL vehicle were within $10-15 \%$ of experimental measurements [23].

\section{NEQAIR Overview}

The Nonequilibrium Air Radiation (NEQAIR) code is a line-by-line radiation code [24] used to analyze the radiative heating on the surface of the high-mass Mars vehicles studied in this paper. The NEQAIR code computes the emission and absorption spectra along a line-of-sight (LOS) for atomic species, molecular species electronic band systems, and infrared band systems. Radiative heating rate is determined using either a tangent slab or spherical cap assumption [25]. Individual electronic transitions are evaluated for atomic and molecular species. The code can model the bound-free and free-free continuum radiation caused by interactions of electrons with neutral and ionized atomic species. NEQAIR is currently used to compute radiative heating as part of the Crew Exploration Vehicle (CEV) Computational Aerosciences Project (CAP) and has been validated against shock tube experimental data in both air [26] and $\mathrm{CO}_{2}$ gas mixtures [27]. The external inputs required by NEQAIR are the (nonequilibrium) temperatures and species number densities along a LOS. In the current implementation, these data are received from the DPLR flow computation.

The NEQAIR calculations performed for the high-mass Mars vehicles included contributions from the atomic lines of N, O, and $\mathrm{C}$ over a spectral range of 855-39600 angstroms. The bound-free and free-continua for $\mathrm{O}$ and $\mathrm{C}$ were included when needed, but the continua contribution could be neglected for entry velocities less than $9.1 \mathrm{~km} / \mathrm{s}$ due to low levels of ionization. Diatomic molecular band systems included in the analysis were $\mathrm{N}_{2}[1+], \mathrm{N}_{2}[2+], \mathrm{N}_{2}[\mathrm{BH} 2], \mathrm{NO}[\beta], \mathrm{NO}[\gamma], \mathrm{NO}[\delta]$, $\mathrm{NO}[\varepsilon], \mathrm{O}_{2}[\mathrm{SR}], \mathrm{CN}$ [violet], $\mathrm{CN}[\mathrm{red}], \mathrm{CO}[4+]$, and $\mathrm{C}_{2}[\mathrm{Swan}]$. The populations of excited energy states were determined using a Boltzmann distribution. The uncertainty of the NEQAIR radiation calculations is somewhat larger than the uncertainty of the convective heating rates computed by DPLR. Cruden et al. [27] estimated a $30 \%$ uncertainty in NEQAIR calculations in $\mathrm{CO}_{2}$ gas mixtures.

A typical spectrum for a high-mass Mars entry vehicle shock layer is shown in Fig. 3. The radiative emission is dominated by the $\mathrm{CO}[4+], \mathrm{CN}$ [violet], $\mathrm{C}_{2}$ [Swan], and $\mathrm{CN}[\mathrm{red}]$ molecular band systems, which account for about $95 \%$ of the overall radiation. The location of these band systems is indicated in Fig. 3. The atomic lines for $\mathrm{C}$ and $\mathrm{O}$ account for most of the remaining $5 \%$ of radiative emission. 


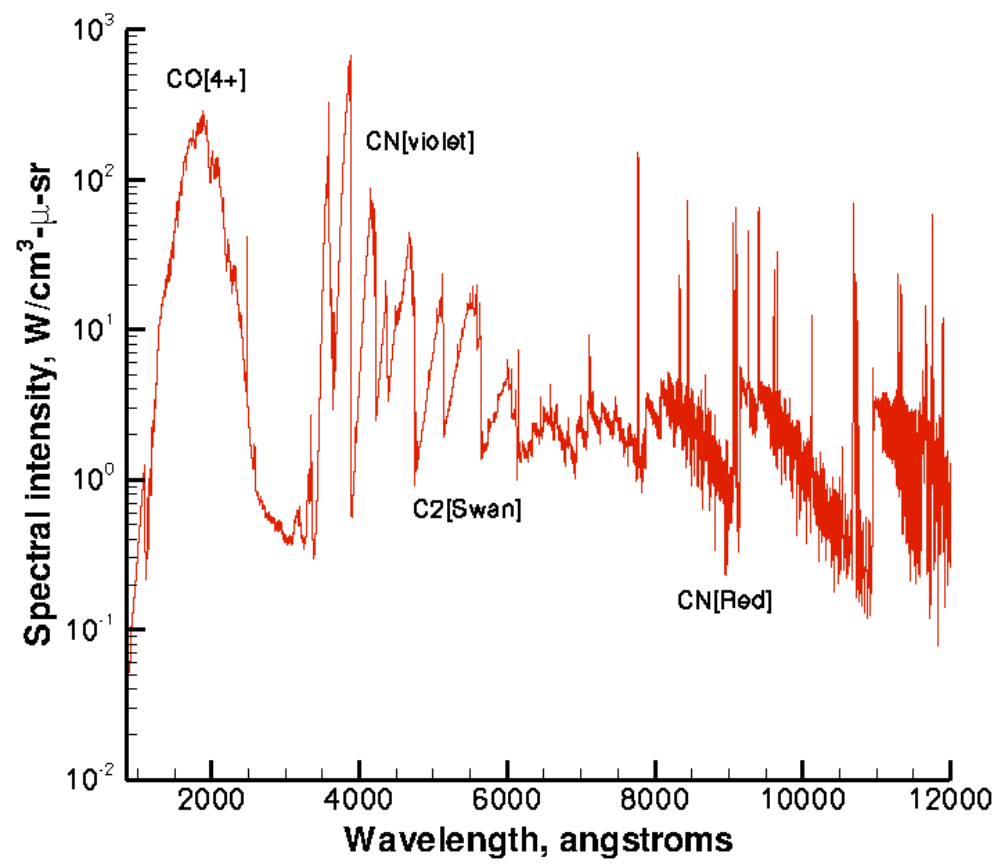

Figure 3. Typical spectrum for high-mass Mars vehicle shock layer.

\section{Fluids-Radiation Coupling}

If the radiant energy is small relative to the total energy of the gas, computing the fluid dynamics and radiation in an uncoupled manner is a reasonable assumption. However, for high-speed entries where the radiant energy is a significant fraction of the total energy, removing the radiative terms from the total energy equation may significantly alter the computed fluid dynamics. Specifically, the radiative energy term typically acts as an energy sink in the shock layer (due to emission) and a source in the boundary layer (due to absorption). If the radiative term is included in the total energy equation, the bow shock standoff distance is typically reduced, and the convective and radiative heating rates at the wall can be lowered as well. This effect is known as radiative cooling.

The amount of coupling between the fluid dynamics and radiation can be estimated by evaluating the Goulard number [28], which is the ratio of the adiabatic radiative energy flux to the total energy flux.

$\Gamma=\frac{2 q_{a d}^{R}}{\frac{1}{2} \rho_{\infty} v_{\infty}^{3}}$

As a rule of thumb, when the Goulard number is larger than 0.01 the fluid dynamics and radiation are considered to be strongly coupled, and the assumption that the inviscid shock layer is adiabatic is no longer valid [29]. Tauber and Wakefield [30] derived an approximate relation for the ratio of the coupled radiative heating to the adiabatic radiative heating as a function of the Goulard number.

$\frac{q_{\text {coup }}^{R}}{q_{a d}^{R}}=\frac{1}{1+\kappa \Gamma^{0.7}}$

For strongly-coupled air radiation (where $\Gamma \geq 0.01$ ), Tauber and Wakefield suggested a value of $\kappa=3$ for entry into the Jovian atmosphere [30], whereas a value of $\kappa=3.45$ has been suggested to model the effects of fluids-radiation coupling in air [29]. Because the absorption in a Martian shock layer will be greater than that seen in air, due to the preponderance of CO in the shock layer, the smaller value of $\kappa=3$ was used in this study. 
The DPLR code, like all Navier-Stokes flow codes, solves the equations representing the conservation of mass, momentum, and energy, including the total energy conservation equation.

$$
\frac{\partial e}{\partial t}+\frac{\partial}{\partial x_{j}}\left((e+p) u_{j}\right)=-\frac{\partial}{\partial x_{j}}\left(q+q_{v j}+q_{e j}\right)-\frac{\partial}{\partial x_{j}}\left(u_{i} \tau_{i j}\right)-\frac{\partial}{\partial x_{j}}\left(u_{s i}\left(h_{s} \delta_{i j}+\tau_{s i j}\right)\right)-\Theta^{R}
$$

The term $\Theta^{R}$ is the radiant energy source term, which is also referred to as the radiant power density. If the fluid dynamics and radiation are uncoupled, i.e. if the fluid dynamics are computed first and the radiation afterwards, the flow is assumed to be adiabatic and the $\Theta^{\mathrm{R}}$ term is removed from the total energy equation. If the fluid dynamics and radiation are coupled, the radiant energy source term is computed for every CFD grid cell and the $\Theta^{R}$ term is maintained inside the total energy equation.

The radiant energy source term is placed in the total energy equation exclusively, because DPLR accounts for the electronic energy terms in the total energy equation. Another approach used by nonequilibrium flow solvers such as LAURA is to include the vibrational, electronic, and free electron energy terms in the vibrational energy equation [25]. In this case, the radiant energy source term would be added to both the vibrational-electronic-electron and total energy equations.

The evaluation of the radiant energy source term can be simplified if the gas in the shock layer is assumed to be opticallythin, meaning that absorption effects can be neglected. If the gas is optically-thin, the radiant energy source term is equal to the spontaneous emission intensity, $E$, of every atomic and rotational line considered added to the background continua multiplied by a view factor of $4 \pi$.

$\Theta^{R}=4 \pi \sum E$

The approach shown in Eq. (4) was taken by Wright et al. [29] when assessing the fluids-radiation coupling effects of a spacecraft entering the atmosphere of Titan.

When absorption effects are included in the analysis, the situation is more complicated, and a general three-dimensional treatment of the radiative source terms is usually prohibitively expensive. Typically, a 1-D infinite tangent slab or spherical cap assumption is made where radiative properties are assumed to only vary along a LOS normal to the body surface. The radiative emission is computed along the LOS, and the results at a given location along the LOS will be influenced by the emission from upstream gas layers. The radiant energy source term for a given cell is equal to the divergence of the radiative heating rate across the LOS grid cell.

$$
\Theta^{R}=\nabla \cdot q_{r}
$$

The spectral intensity, $I_{i}$, at a given wavelength, $\lambda$, striking or passing through the surface of a LOS grid cell is a function of the incident intensity, $I_{\lambda}^{o}$, from the upstream LOS surface, the volumetric absorption coefficient, $\alpha_{i}$, the width of the LOS grid cell, $w$, and the Black Body intensity, $B$.

$$
I_{\lambda}=I_{\lambda}^{0} e^{-\alpha_{\lambda} w}+B \lambda\left(1-e^{-\alpha_{\lambda} w}\right)
$$

The radiative heating rate, $q_{r}$, at a LOS grid cell surface is found by integrating the spectral intensity over the wavelength and solid angle ranges being considered.

$$
q_{r}=\iint I_{\lambda} d \lambda d \Omega
$$

For the NEQAIR computations, the LOS is divided into a series of one-dimensional grid cells, and the radiative emission, absorption, and spectral intensity are computed at every LOS cell. Since the radiant energy source term must be evaluated at every CFD grid cell, it simplifies matters to define the line-of-sight grid to be the same as the normal grid lines of the CFD grid, an asumption that is valid if the normal grid lines are indeed normal to the surface all the way out to the bow shock. However, the computer time required for the coupled fluids-radiation solution is proportional to the number of points in the NEQAIR LOS. It turns out that the normal grid resolution required for DPLR to accurately resolve the surface convective heating rate is more than is needed by NEQAIR for the radiation calculation. It was possible to "thin" the NEQAIR LOS by 
only considering every other normal CFD grid point. Linear interpolation was used to determine the radiant energy source terms for the normal grid points removed from the NEQAIR calculation. This LOS grid thinning approach reduced the time necessary to perform a coupled fluids-radiation calculation by a factor of 2 . The error between the full and "thinned" LOS was in the $5-10 \%$ range.

As part of the MAT Element of the EDL project, the NEQAIR radiation code was incorporated into the DPLR Navier-Stokes flow solver in that the NEQAIR subroutines are now callable subroutines of DPLR. The radiative terms are loosely-coupled to the fluid dynamics, because the radiant energy density terms are not updated every CFD iteration. The usual solution process starts with a DPLR solution run to convergence with the radiative terms turned off (i.e. under an adiabatic assumption). When the adiabatic solution is complete, a flag in the DPLR input file is set to activate the radiative terms, which are then updated every 2000 CFD iterations. Typically only 2-3 updates to the radiative source terms are required to achieve heating rate convergence.

The coupled DPLR-NEQAIR code was previously applied to computing the convective and radiative heating rates over the FIRE II flight vehicle entering the Earth's atmosphere [31]. A comparison between the uncoupled and coupled total heating rate predictions at the 1643 second trajectory point are shown in Fig. 4. At the 1643 second trajectory point, there was a significant effect (i.e. reduction) in the combined convective and radiative heating rates due to fluids-radiation coupling, and the coupled results are closer to the FIRE II flight measurements.

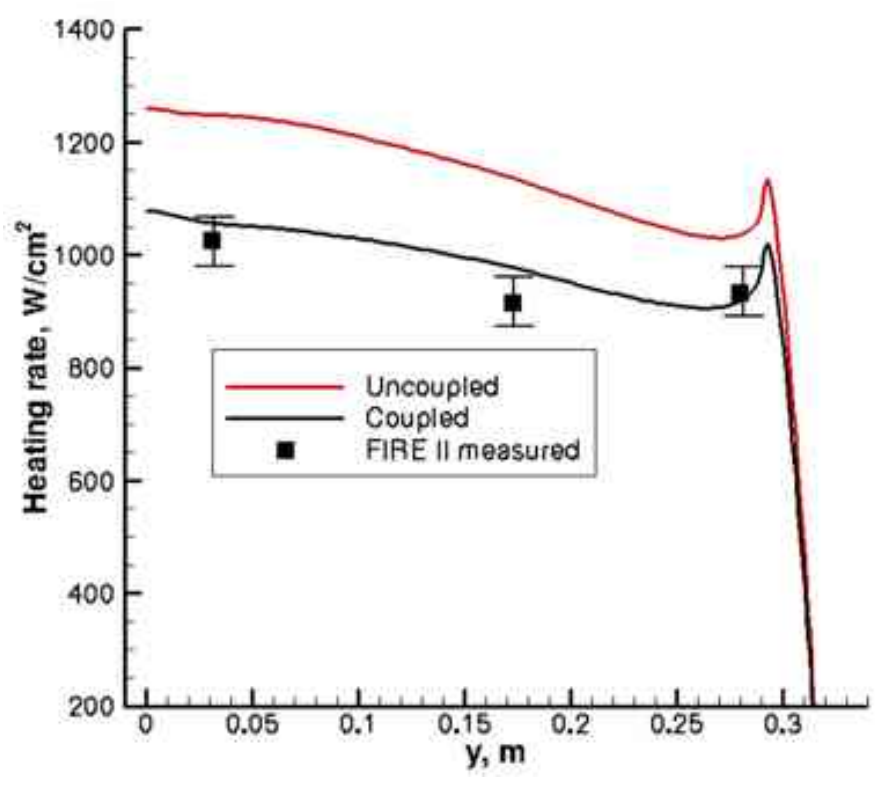

Figure 4. Effects of fluids-radiation coupling, FIRE II flight test.

The high-mass Mars CFD computations presented in this paper were generated using NASA's NAS Supercomputer facility. DPLR is intended to be run in a parallel fashion where the overall volume grid is split up into smaller sub-grids with each sub-grid assigned to a different computer processor. The MSL-based solutions were run on 208 processors, and the Ellipsled solutions were run using 198 processors. The initial CFD solution with the radiation terms turned off required approximately 16000 iterations and 10 hours of CPU time per processor. It was during this initial computation that the grid adaption process to align the outer boundary of the CFD grid to the bow shock was performed. After the initial solution had converged, the radiation terms were activated. Three additional runs were performed consisting of a radiative source term update followed by 2000 iterations on the fluid dynamics. Each radiation source term update and 2000 iteration run required approximately 16 hours for the MSL-based vehicle and somewhat longer for the Ellipsled because the Ellipsled grid had more surface grid points (the NEQAIR routines are called for every normal grid line). The total CPU time required for a 3-D coupled DPLRNEQAIR solution was therefore approximately 55-60 hours for the MSL-based vehicle, compared to 10 hours if the radiation terms are omitted. 


\section{$\underline{\text { Grids }}$}

The initial CFD grids used in this work were based on those used in previous MSL and Ellipsled CFD studies. For the MSLbased high-mass Mars entry vehicle, the grids used by Edquist et al. [18] for their MSL analysis were scaled up to a $15 \mathrm{~m}$ diameter and used as starting grids in this study. Only the heatshield was considered, and the surface grid is shown in Fig. 5a. The grid is constructed in four zones including a $33 \times 33$ surface grid zone at the nose of the vehicle and three $65 \times 33$ surface zones around the rest of the heatshield. There were 129 normal grid lines.

In a similar fashion, the Ellipsled grid used by Garcia et al. [8] was used as the starting grid for the Ellipsled CFD solutions generated in this study. The Ellipsled surface grid is shown in Fig. 5b. It consists of six $65 \times 65$ surface grid zones. As can be seen in Fig. 5b, only the windward surfaces of the vehicle are modeled. The Ellipsled enters the Martian atmosphere at an angle of attack in excess of 50 degrees. At such a high angle of attack, the outer boundary of the leeside grids, if they were included, would be a great distance from the surface of the body resulting in poor grid resolution. In addition, the heating rates would be low on the leeside of the vehicle. Because of these factors, the leeside Ellipsled grid zones were omitted from consideration. There were 81 normal grid lines for the Ellipsled grid.

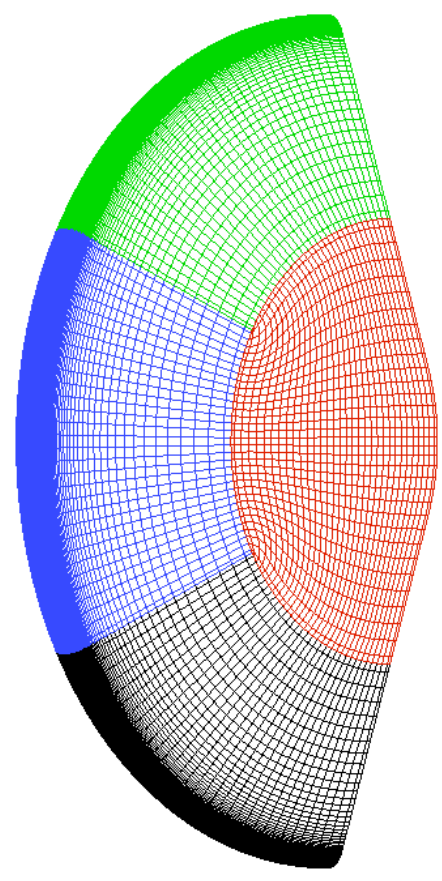

(a)

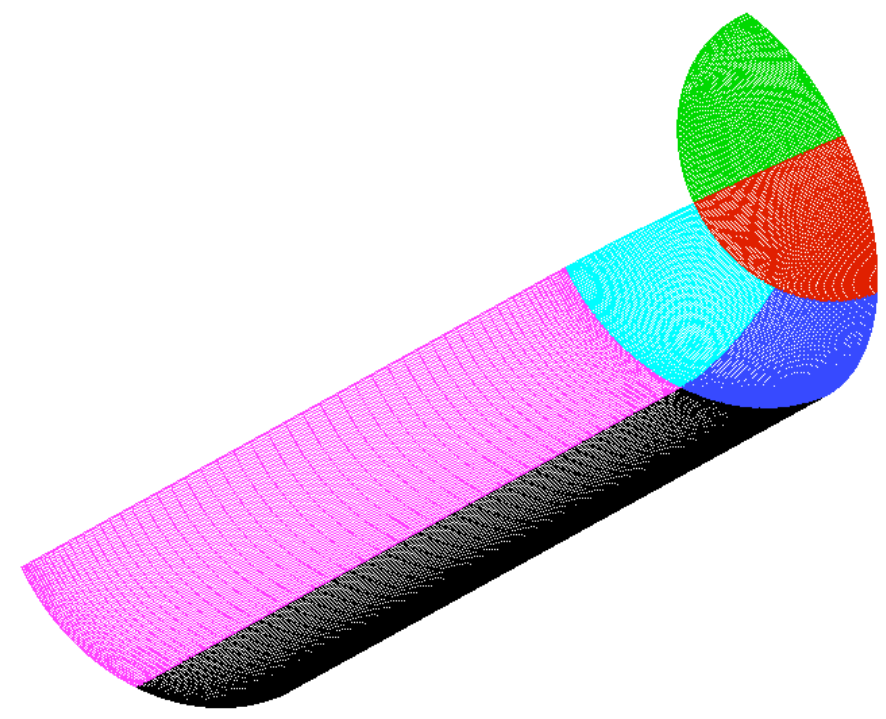

(b)

Figure 5. CFD surface grids. (a) MSL-based grid. (b) Ellipsled.

\section{$\underline{\text { Trajectories }}$}

Human missions to Mars require a fast transfer orbit from Earth to Mars in order to reduce crew exposure to cosmic radiation [4]. The transfer orbit that minimizes travel time from Earth to Mars is known as a Type-I transfer orbit, where aphelion occurs after flying by Mars. The disadvantage of Type-I orbits is the entry speeds, and corresponding heating rates, are high. Another consideration when designing a human-class Mars mission is whether a direct-entry, aerobraking, or aerocapture trajectory should be used. An aerocapture entry trajectory consists of a single-pass atmospheric maneuver to transfer from a heliocentric arrival trajectory into a Mars staging orbit. The payload would then descend to the surface of the planet from the staging orbit. For human missions to Mars, aerocapture has advantages in terms of lower vehicle mass, mission flexibility, and lower peak heating rates as compared to direct entries, and significantly less time in orbit relative to aerobraking entries [1]. It is for these reasons that aerocapture trajectories are used in this study.

There are many different types of idealized aerocapture trajectories to a specific apoapsis altitude. The limiting trajectories are the undershoot, or lift-up, trajectory where the lift vector of the vehicle always points up and the overshoot, or lift-down, trajectory where the lift vector always points down. The undershoot trajectory has the steepest entry angle, highest peak deceleration and peak heating rate, but the smallest total integrated heat load. The overshoot trajectory has the shallowest entry angle, lowest peak deceleration and peak heating rate, but the highest integrated heat load. Practical aerocapture would 
use a mid-corridor trajectory with an entry angle between undershoot and overshoot values. The type of mid-corridor trajectory used in this study uses peak deceleration as a target constraint. The maximum deceleration limit for a crew of deconditioned astronauts used in Refs. 1-8 varied from 3 to 5 Earth-g's. A deceleration limit of $4 \mathrm{~g}$ is used in this paper as was used in Ref. 3.

Another parameter that must be determined for a high-mass Mars entry study is the range of entry velocities to consider. Figure 6, taken from Ref. 2, shows the entry corridor for a $15 \mathrm{~m}$ diameter vehicle with an entry mass of 100 metric tons $(100000 \mathrm{~kg})$, lift-to-drag ratio (L/D) of 0.3 , and ballistic coefficient of $400 \mathrm{~kg} / \mathrm{m}^{2}$. These values are typical for a 70 -degree sphere cone geometry such as the scaled-up MSL aeroshell vehicle used in this study. The total entry corridor, the difference between the lift-down and lift-up or peak deceleration limit entry angles, is usually constrained to be greater than $1 \mathrm{deg}$. This $1 \mathrm{deg}$. constraint thus implies a peak entry velocity of $9.1 \mathrm{~km} / \mathrm{s}$ for this geometry. Entry velocities between 6.5 and $9.1 \mathrm{~km} / \mathrm{s}$ are used in this study.

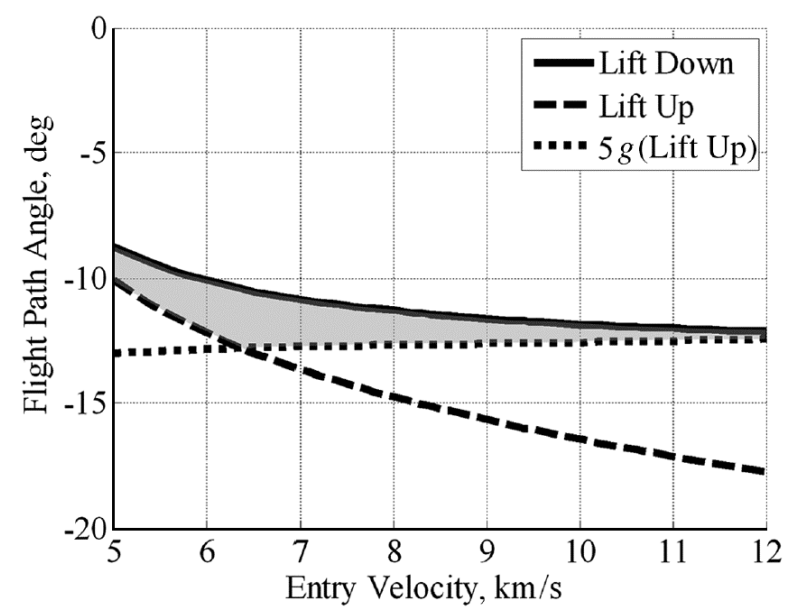

Figure 6. Entry corridor for an $\mathrm{L} / \mathrm{D}=\mathbf{0 . 3}$ vehicle

The trajectories used in this study were generated by the Traj trajectory analysis code [32-33]. Traj can analyze missions to most planetary bodies with an atmosphere in our solar system. It includes three-degrees-of-freedom (3-DoF) and six-degreesof-freedom trajectory simulation, aerothermodynamic heating prediction including real gas effects, thermal protection system (TPS) material response, Monte-Carlo and aerocapture analysis. Traj computes the trajectory that the vehicle flies through the atmosphere, the forces and thermal loads experienced by the vehicle throughout the flight, and when appropriate the thickness and mass of TPS material required to keep the temperature of the spacecraft structure within specified operational limits.

The Mars atmospheric model used by Traj for this study was reduced directly from the Mars Pathfinder inertial measurement unit data [34]. For the MSL-based 70-degree sphere cone, the L/D at peak dynamic pressure was 0.29. Entry velocities of 6.5, $7.0,8.0,8.5$, and $9.1 \mathrm{~km} / \mathrm{s}$ were considered. The angle of attack for all entry velocities was held constant at $-14.0 \mathrm{deg}$. The entry mass for the a ballistic coefficient of $400 \mathrm{~kg} / \mathrm{m}^{2}$ was computed by Traj to be 102.5 metric tons. Entry angles varied from -12.2 to -12.85 degrees. A heavier vehicle was also considered with a ballistic coefficient of $640 \mathrm{~kg} / \mathrm{m}^{2}$, an entry mass of 165.2 metric tons, and an entry velocity of $9.1 \mathrm{~km} / \mathrm{s}$.

The Ellipsled was modeled as a sphere cone with a half angle of $0.1 \mathrm{deg}$ (the frustum was effectively a cylinder). The aerodynamics for the Ellipsled was based upon a closed form solution of the Modified Newtonian aerodynamic model described in Ref. 32. This closed solution models a vehicle at an angle-of-attack with wake shadow effects. For the Ellipsled, a trim angle of attack of 53.84 yielded an L/D of 0.5 at peak dynamic pressure. Entry velocities of 7.0, 8.0, 8,5, and $9.1 \mathrm{~km} / \mathrm{s}$ were analyzed for an Ellipsled with a ballistic coefficient of $459 \mathrm{~kg} / \mathrm{m}^{2}$ and an entry mass of 109.5 metric tons. A heavier vehicle was also considered with a ballistic coefficient of $705 \mathrm{~kg} / \mathrm{m}^{2}$, an entry mass of 164.3 metric tons, and an entry velocity of $9.1 \mathrm{~km} / \mathrm{s}$.

The resulting trajectories for the Ellipsled geometry as a function of inertial entry velocity and entry mass are shown in Fig. 7. The first four curves are for a vehicle mass of 109.5 metric tons, and the black line curve is for the 164 metric ton vehicle. The minimum altitudes reached (which do not correspond to the peak heating locations) ranges from 30.1 to $34.5 \mathrm{~km}$. The MSL-based 70-degree sphere cone trajectories show similar characteristics. 


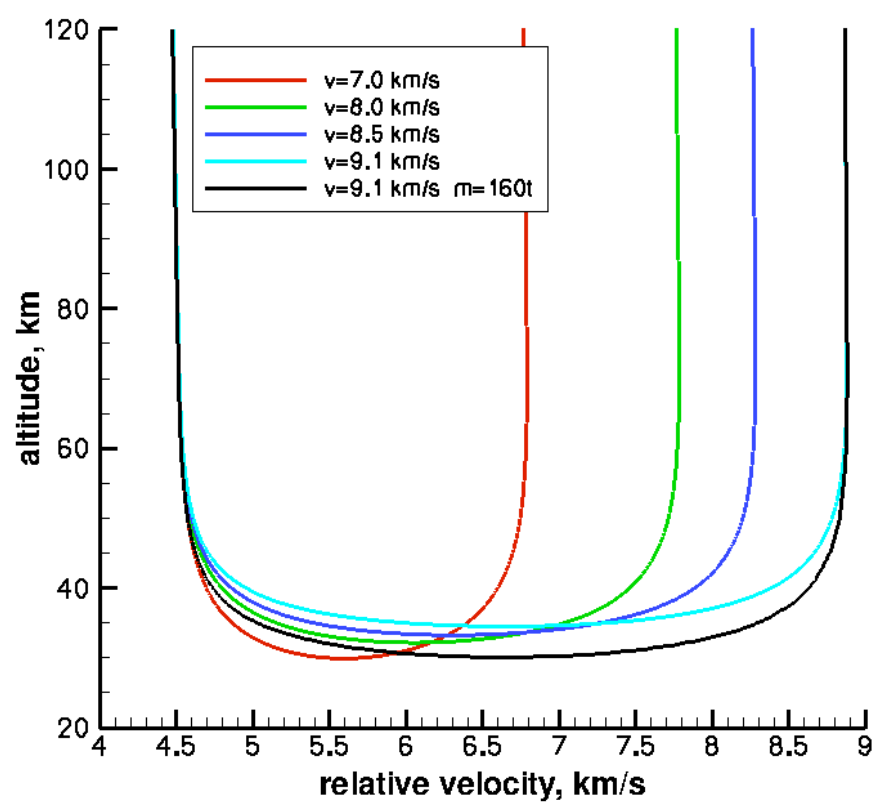

Figure 7. Trajectories for Ellipsled geometry.

Again, it should be noted that the trajectories used in this paper are idealized, e.g. a real spacecraft flying a lifting trajectory would not hold its bank angle at an exact constant value and/or could not instantaneously change its bank angle, i.e. it takes time for the bank angle to change from one value to another due to the vehicle's moment of inertia. Also a real vehicle will not fly at a fixed angle-of-attack during the entire atmospheric descent and ascent but instead will have a trim angle-of-attack that is dependent upon Mach number and an instantaneous angle-of-attack that will oscillate around the trim angle-of-attack. However, the idealized trajectories generated by Traj were deemed sufficient for the purpose of this paper, which is to assess the effect of entry velocity on the convective and radiative heating rates of a high-mass Mars vehicle.

\section{Freestream Conditions}

Coupled DPLR-NEQAIR solutions were computed at the peak heating point of the trajectories described in the previous section. The peak heating point for each trajectory was estimated according to the Fay-Riddell approximation [35] modified for $\mathrm{CO}_{2}$ gas mixtures. The freestream values at the peak heating point for the MSL-based vehicle are shown in Table 1. The first five rows are for a vehicle with an entry mass of 102.5 metric tons. The last row in the table is for the heavier, 165 metric ton, vehicle. The angle of attack for all of the MSL-based vehicle trajectories was held constant at 14.0 degrees.

Table 1. Peak heating freestream conditions, MSL-based vehicle.

\begin{tabular}{ccccc}
\hline \hline entry velocity, $\mathbf{~ m} / \mathbf{s}$ & altitude, $\mathbf{k m}$ & velocity, $\mathbf{~} / \mathbf{s}$ & density, $\mathbf{k g} / \mathbf{m}^{\mathbf{3}}$ & temperature $\mathbf{K}$ \\
\hline 6.5 & 35.85 & 5808 & $5.45 \mathrm{e}-4$ & 171.6 \\
7.0 & 33.56 & 6193 & $7.00 \mathrm{e}-4$ & 172.2 \\
8.0 & 36.80 & 7143 & $4.90 \mathrm{e}-4$ & 172.1 \\
8.5 & 38.16 & 7640 & $4.14 \mathrm{e}-4$ & 174.8 \\
9.1 & 38.02 & 8221 & $4.22 \mathrm{e}-4$ & 174.3 \\
$9.1(165 \mathrm{t})$ & 35.04 & 8235 & $5.94 \mathrm{e}-4$ & 172.2 \\
\hline \hline
\end{tabular}


The peak heating freestream values for the Ellipsled vehicle are shown in Table 2. The first five rows are for a vehicle with an entry mass of 109.5 metric tons. The last row is for the heavier, 164 metric ton, vehicle. The angle of attack for all of the Ellipsled trajectories was held constant at 53.8 degrees. In comparing the MSL-based and Ellipsled conditions for a fixed entry velocity, the Ellipsled dips a bit lower in the Martian atmosphere, and the velocity at the peak heating point for the MSL-based vehicle is slightly higher.

Table 2. Peak heating freestream conditions, Ellipsled vehicle.

\begin{tabular}{ccccc}
\hline \hline entry velocity, $\mathbf{k m} / \mathbf{s}$ & altitude, $\mathbf{k m}$ & velocity, $\mathbf{m} / \mathbf{s}$ & density, $\mathbf{k g} / \mathbf{m 3}$ & temperature, K \\
7.0 & 33.76 & 6226 & $6.86 \mathrm{e}-4$ & 172.0 \\
8.0 & 35.92 & 7146 & $5.41 \mathrm{e}-4$ & 171.5 \\
8.5 & 36.63 & 7558 & $4.99 \mathrm{e}-4$ & 171.9 \\
9.1 & 37.90 & 8137 & $4.28 \mathrm{e}-4$ & 174.0 \\
$9.1(164 \mathrm{t})$ & 34.26 & 8206 & $6.49 \mathrm{e}-4$ & 171.8 \\
\hline \hline
\end{tabular}

\section{$\underline{\text { Results - General Flow Features }}$}

Due to the size of the high-mass Mars entry vehicles, the flow over the windward surfaces is expected to be turbulent at the peak heating trajectory point. To examine the differences between laminar and turbulent heating rates, laminar DPLR CFD solutions were performed for the MSL-based vehicle at an entry velocity of $6.5 \mathrm{~km} / \mathrm{s}$ and for the Ellipsled at an entry velocity of $7.0 \mathrm{~km} / \mathrm{s}$. The heating rate contours are shown in Fig. 8. The peak laminar convective heating rates for both the MSLbased and Ellipsled vehicles occur at the stagnation point, fairly close to the nose of the vehicle. In contrast, the location of peak turbulent convective heating on the MSL-based vehicle is located on the leeside shoulder. For the Ellipsled, the peak turbulent convective heating occurs on the cylindrical portion of the vehicle downstream from the stagnation point. The turbulent augmentation factor for convective heating (the ratio of the peak turbulent to peak laminar values) is 3.2 for the MSL-based vehicle and 3.5 for the Ellipsled.
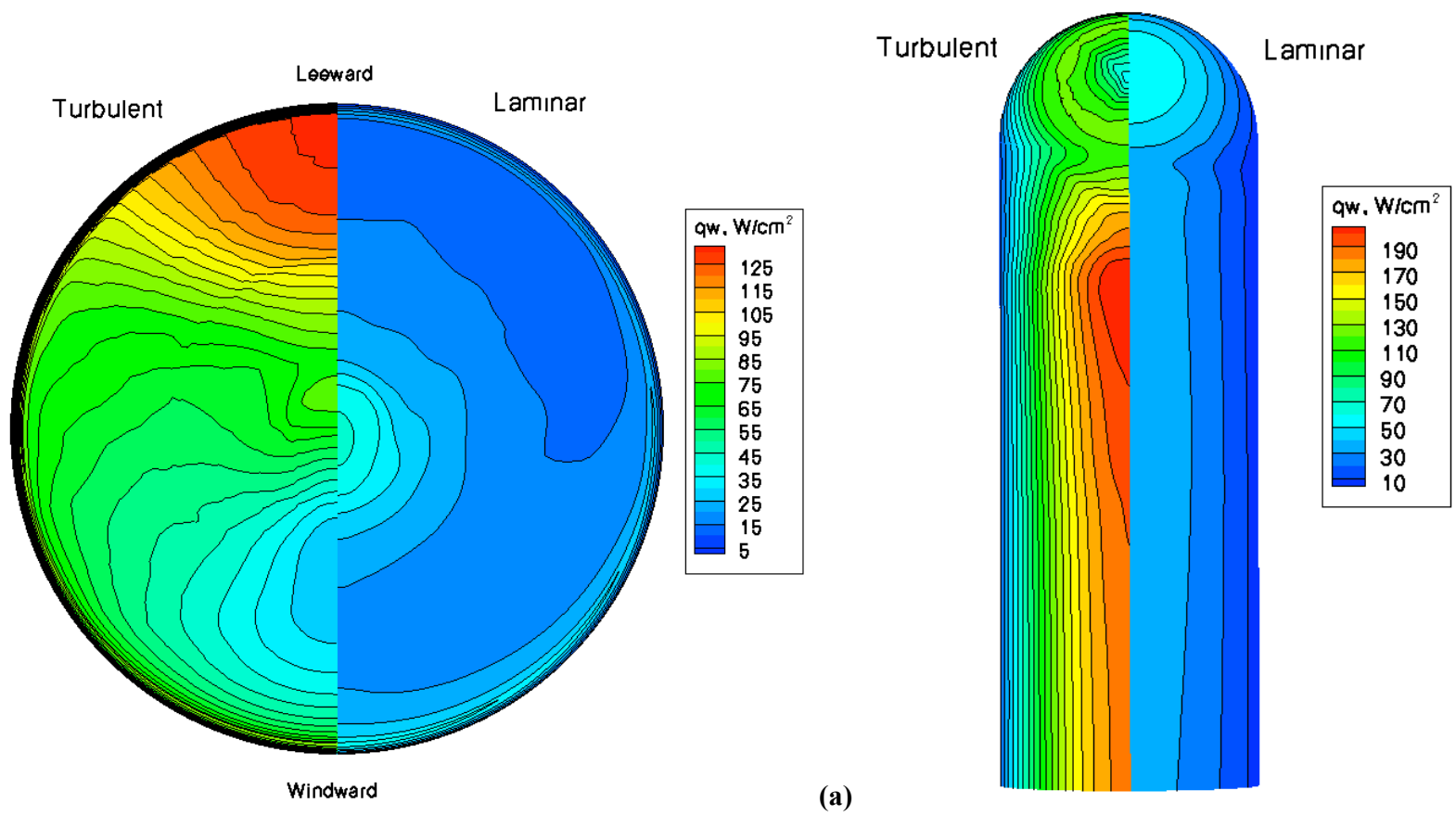

(b)

Figure 8. Comparison of laminar and turbulent convective heating rate contours. (a) MSL-based vehicle, $\mathrm{v}=6.5 \mathrm{~km} / \mathrm{s}$. (b) Ellipsled, $\mathrm{v}=7.0 \mathrm{~km} / \mathrm{s}$.

One of the advantages of the coupled DPLR-NEQAIR code is it allows the radiative heating rate to be calculated at every surface grid point as part of the CFD solution process. Figure 9 presents the convective and radiative heating rate contours for an entry velocity of $8.5 \mathrm{~km} / \mathrm{s}$ for both the MSL-based 70-degree sphere cone vehicle and the Ellipsled. The contour levels are 
the same for both plots allowing a comparison to be made between the MSL-based and Ellipsled geometries. The peak radiative heating rate for both vehicles occurs at the stagnation point. The peak radiative heating rate value of $116.8 \mathrm{~W} / \mathrm{cm}^{2}$ for the MSL-based vehicle is higher than the peak value of $81.4 \mathrm{~W} / \mathrm{cm}^{2}$ for the Ellipsled. When flow values along the stagnation line LOS are examined, the shock-layer temperature and number density values are similar for the MSL-based and Ellipsled vehicles, but the shock-standoff distance is less for the Ellipsled, which reduces the surface radiative heating rate. The Ellipsled has a higher peak convective heating rate of $288.4 \mathrm{~W} / \mathrm{cm}^{2}$ as compared to the MSL-based vehicle, which has a peak convective heating rate of $224.0 \mathrm{~W} / \mathrm{cm}^{2}$.

The general heating rate contour features shown in Fig. 9 are similar for all the entry velocity trajectories analyzed in this study. The peak radiative heating rate occurs where the turbulent convective heating rate is relatively low and vice-versa, a situation advantageous for the purposes of TPS sizing.
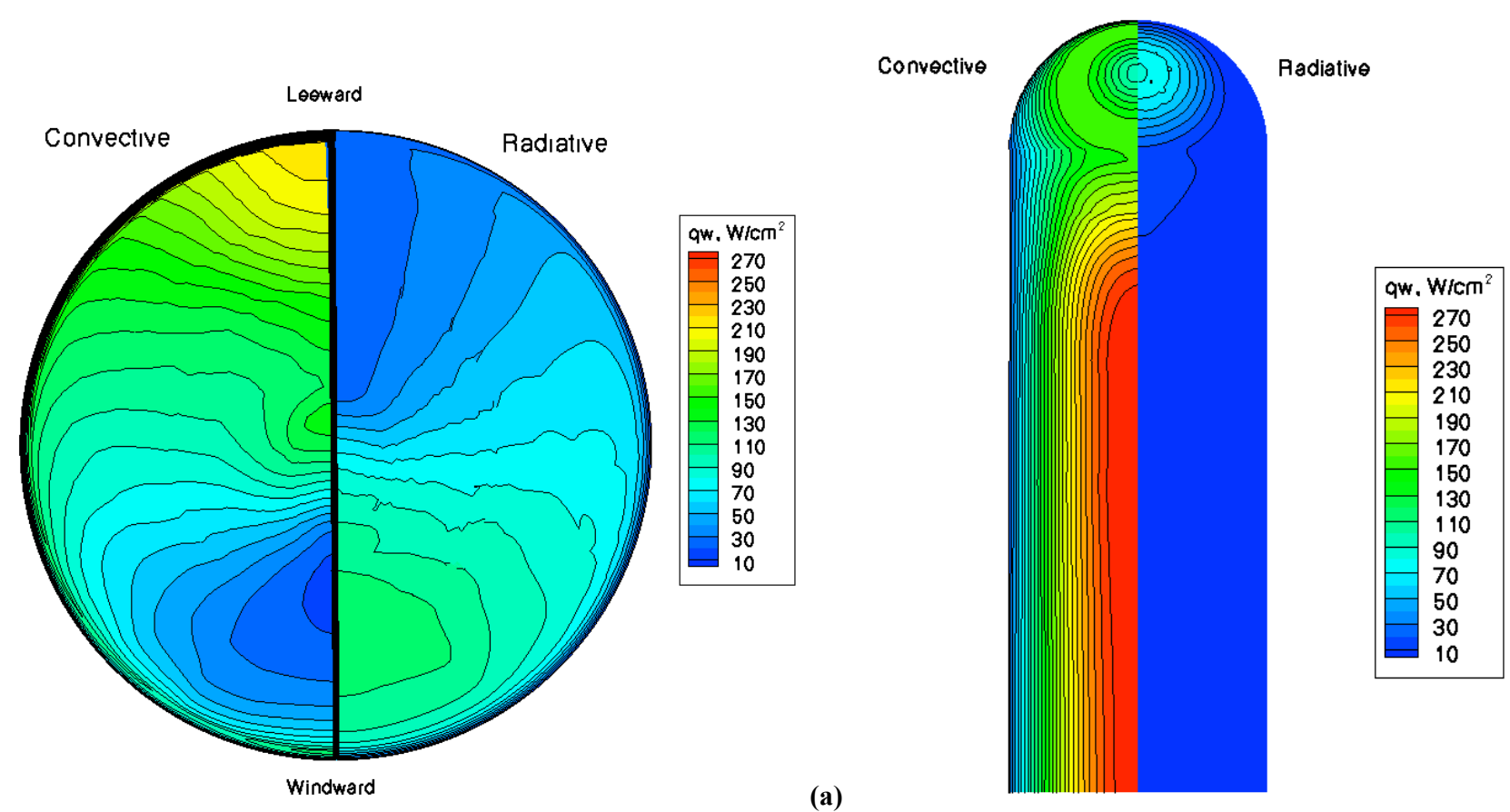

(b)

Figure 9. Comparison of convective and radiative heating rates for $8.5 \mathrm{~km} / \mathrm{s}$ entry velocity. (a) MSL-based vehicle. (b) Ellipsled.

\section{$\underline{\text { Results - Effect of Fluids-Radiation Coupling }}$}

If the net emission of radiant energy in a CFD grid cell is positive, including the radiative term in the total energy equation will cool the flow and reduce the shock standoff distance. Conversely, if the net emission of radiant energy is negative, due to absorption effects in the boundary layer for instance, the radiative source term will add energy to the flow. According to the Goulard number relation shown in Eq. (1), the impact of fluids-radiation coupling is proportional to the ratio of the adiabatic (i.e.uncoupled) radiative heating divided to the total energy flux. Increasing the freestream density and velocity, which will increase radiative heating, won't necessarily increase the effect of fluids-radiation coupling because the density and velocity appear in the denominator of Eq. (1) as well.

The effects of fluids-radiation coupling for the MSL-based vehicle for an entry velocity of $8.5 \mathrm{~km} / \mathrm{s}$ are shown in Fig. 10. The temperature profiles along the stagnation line are displayed in Fig. 10a. The stagnation point is the location of highest radiative heating, and therefore also where the greatest fluids-radiation coupling effect will occur. When fluids-radiation coupling is considered, the shock standoff distance at the stagnation point decreases by about $10 \%$. The convective and radiative heating rate profiles down the centerline of the heatshield are shown in Fig. 10b. The coupled solution shows a 9\% decrease in the radiative heating rate compared to the uncoupled solution. The coupling effect decreases on the leeside of the vehicle, because the level of radiative heating decreases as well. There is a very slight increase in the convective heating rate due to radiative absorption effects in the boundary layer. 

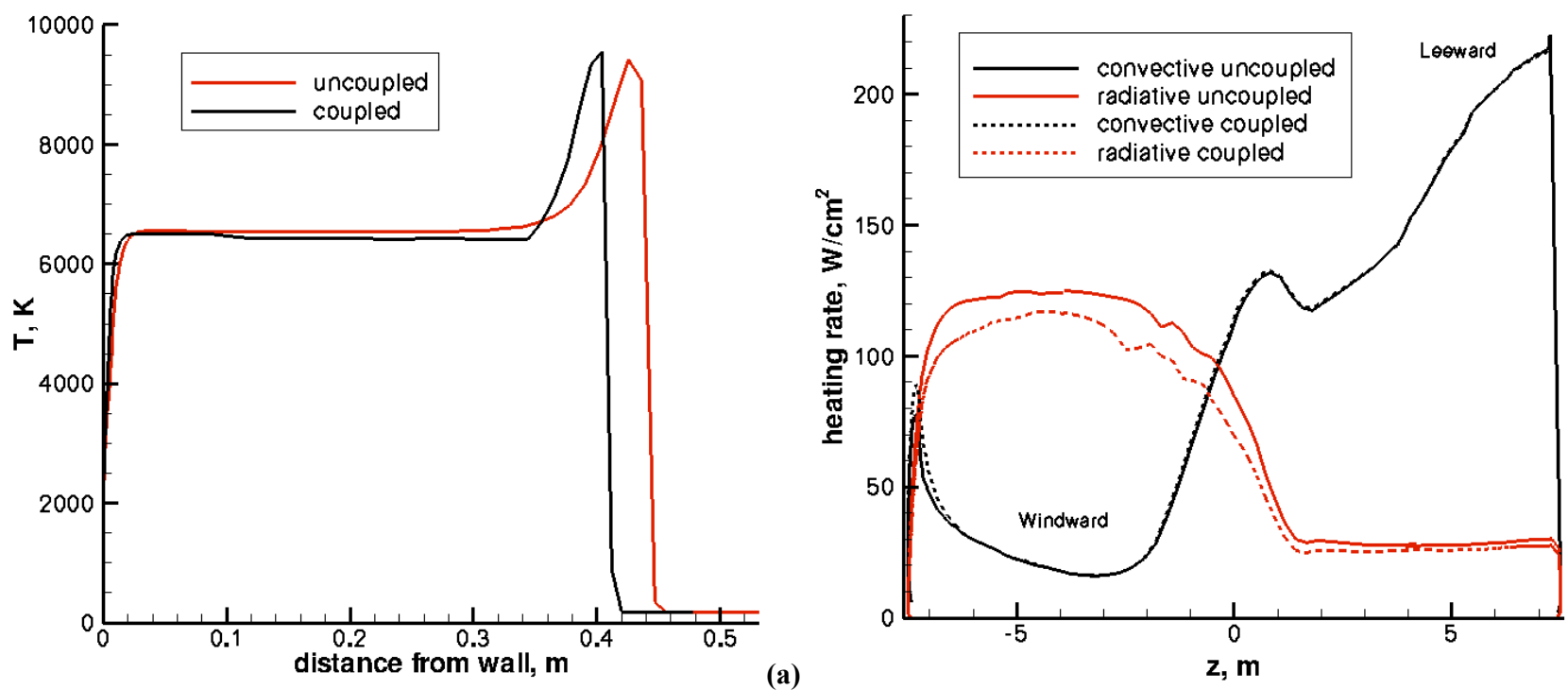

(b)

Figure 10. Effects of fluids-radiation coupling, MSL-based vehicle at entry velocity of $8.5 \mathrm{~km} / \mathrm{s}$. (a) stagnation line temperature profiles. (b) surface heating rates.

The ratios of coupled to uncoupled radiative heating rate at the stagnation point for the MSL-based vehicle at each of the entry velocities considered are presented in Figure 11. Shown in the figure are the values predicted by the Tauber-Wakefield relation from Eq. (2) as well as the results calculated from the DPLR-NEQAIR solutions. There are low levels of radiative heating, and therefore limited coupling effects, at the lower entry velocities of 6.5 and $7.0 \mathrm{~km} / \mathrm{s}$. Both the Tauber-Wakefield and DPLR-NEQAIR results predict increasing fluids-radiation coupling effects as the entry velocity increases to $8.5 \mathrm{~km} / \mathrm{s}$. The DPLR-NEQAIR solutions show less fluids-radiation coupling effects than the Tauber-Wakefield formula for every entry velocity. The difference is particularly noticeable at the $8.0 \mathrm{~km} / \mathrm{s}$ entry velocity and for the $9.1 \mathrm{~km} / \mathrm{s}$ condition with the 165 metric ton vehicle. The Tauber-Wakefield correlation is based on numerical calculations for air and $\mathrm{H}_{2}-\mathrm{He}$ gas mixtures, and may not properly account for the absorption effects due to high $\mathrm{CO}$ concentrations in a Martian shock layer.

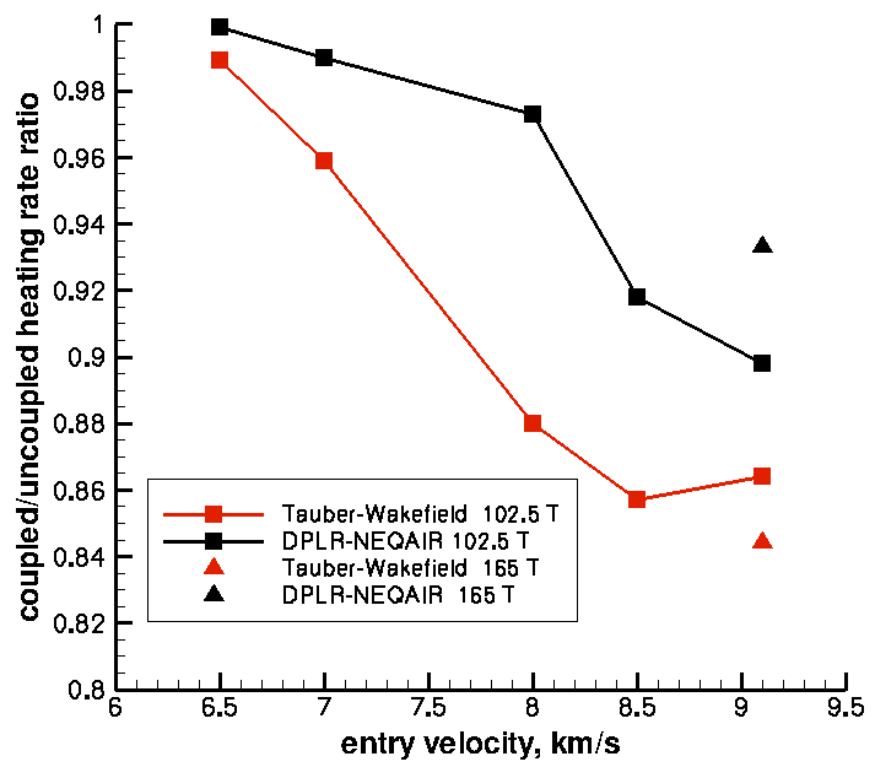

Figure 11. Ratio of coupled to uncoupled radiative heating rates, MSL-based 70-degree sphere cone vehicle.

The stagnation line temperature profile for the Ellipsled vehicle for an entry velocity of $8.5 \mathrm{~km} / \mathrm{s}$ is shown in Fig. 12a. The shock standoff distance is smaller for the Ellipsled than it is for the MSL-based vehicle, and the effect of fluids-radiation coupling on the shock standoff distance is less for the Ellipsled as well. The decrease in shock standoff for the Ellipsled at these conditions was about $5 \%$. The coupled and uncoupled heating rate profiles are shown in Fig. $12 \mathrm{~b}$. There is a $16 \%$ decrease in radiative heating at the stagnation point for the coupled solution, but this difference between the coupled and 
uncoupled radiative heating rates decreases rapidly with increasing distance from the stagnation point. There is a barely noticeable increase in convective heating for the coupled solution.
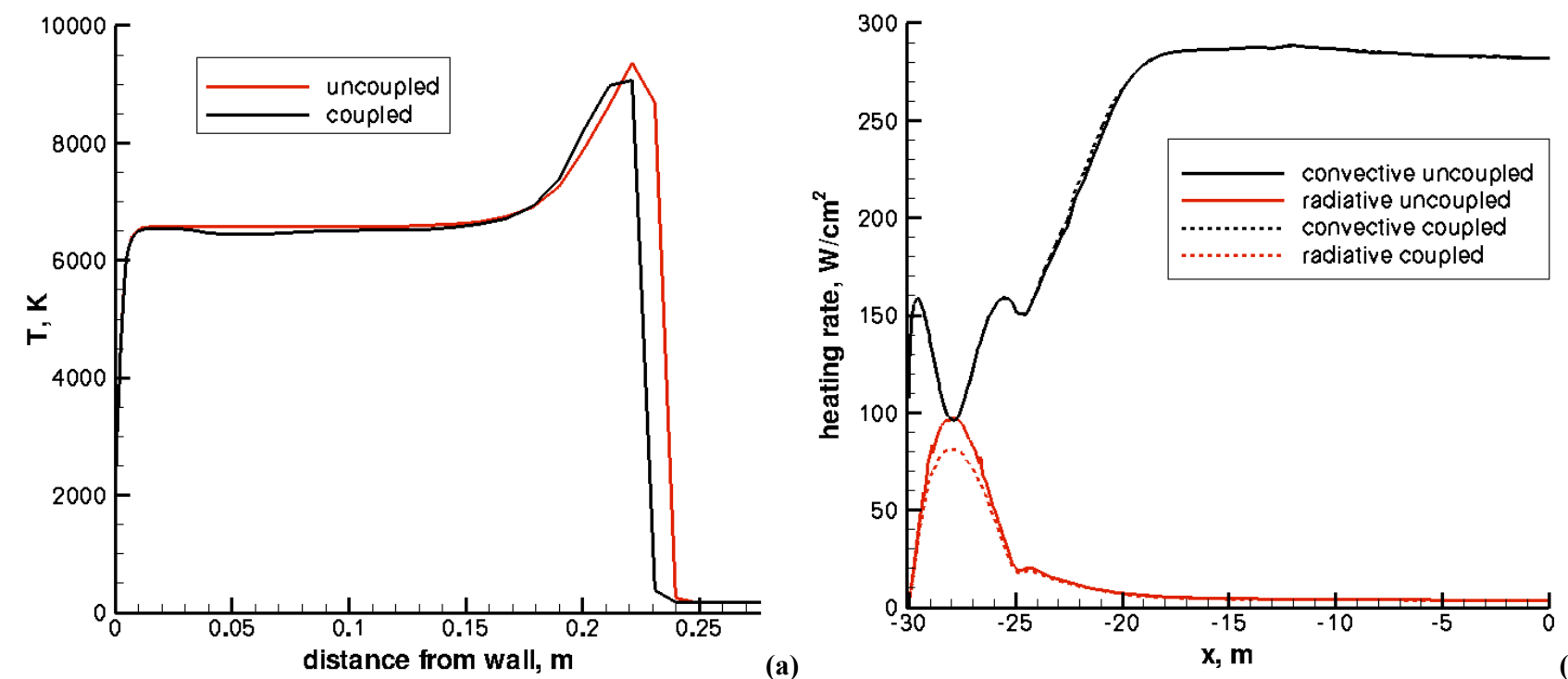

Figure 12. Effects of fluids-radiation coupling, Ellipsled vehicle at entry velocity of $8.5 \mathrm{~km} / \mathrm{s}$. (a) stagnation line temperature profiles. (b) surface heating rates.

The comparison of stagnation point radiative heating rate ratios for the Ellipsled for all entry velocities considered is shown in Fig. 13. Similar to the MSL-based vehicle results, there is little fluids-radiation coupling for the Ellipsled at an entry velocity of $7.0 \mathrm{~km} / \mathrm{s}$. Coupling effects increase with increasing entry velocity. At an entry velocity of $9.1 \mathrm{~km} / \mathrm{s}$, the fluidradiation coupling reduces the stagnation point radiative heating by $17 \%$. As was the case with the MSL-based vehicle, there are discrepancies between the ratios predicted by Tauber-Wakefield and the present DPLR-NEQAIR results for the $8.0 \mathrm{~km} / \mathrm{s}$ and $9.1 \mathrm{~km} / \mathrm{s}, 164$ metric ton conditions. In both cases, the DPLR-NEQAIR solutions predict less fluids-radiation coupling than does the Tauber-Wakefield correlation.

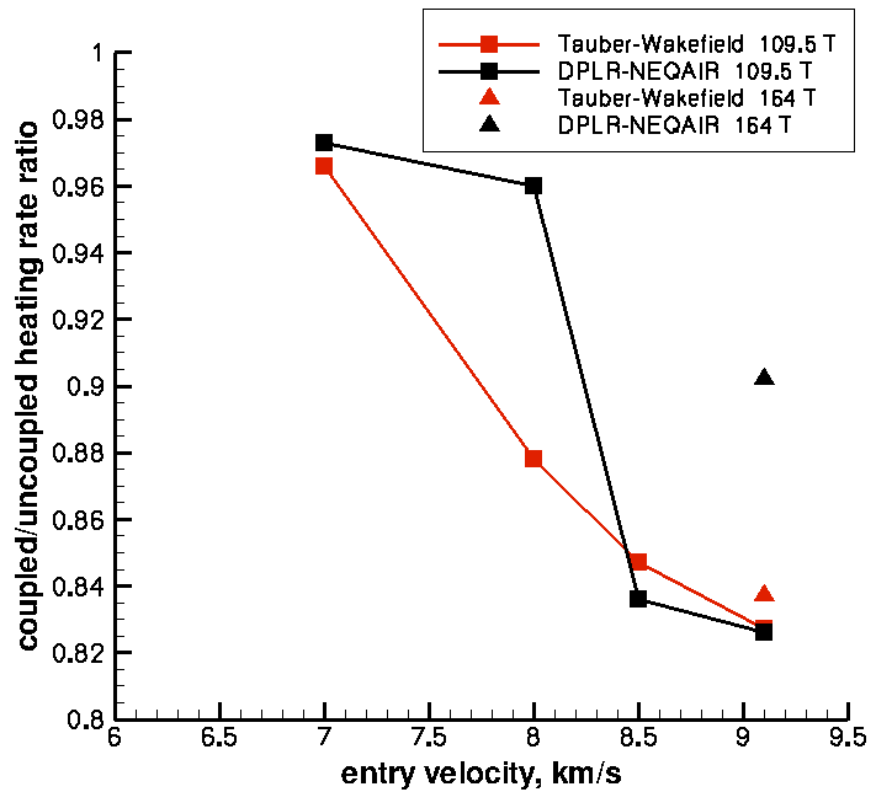

Figure 13. Ratio of coupled to uncoupled radiative heating rates, Ellipsled vehicle. 


\section{Results - Heating Rates as a Function of Entry Velocity}

The convective heating profiles along the centerline of the MSL-based vehicle are shown in Fig. 14a. A characteristic of turbulent flow over 70-degree sphere cone geometries is that the peak convective heating rate occurs on the leeside of the heatshield. At an entry velocity of $6.5 \mathrm{~km} / \mathrm{s}$, the peak convective heating rate is $132.5 \mathrm{~W} / \mathrm{cm}^{2}$. The peak turbulent convective heating rate increases with increasing entry velocity. It reaches a value of $287.0 \mathrm{~W} / \mathrm{cm}^{2}$ for the $9.1 \mathrm{~km} / \mathrm{s}, 102.5$ metric ton vehicle and $376.5 \mathrm{~W} / \mathrm{cm}^{2}$ for the $9.1 \mathrm{~km} / \mathrm{s}, 165$ metric ton vehicle.

Radiative heating rate profiles for the MSL-based vehicle are presented in Fig. 14b. The peak radiative heating rate occurs at or near the stagnation point on the vehicle, which is the location of lowest turbulent convective heating rate. The peak radiation value increases with increasing entry velocity. Radiative heating is negligible at an entry velocity of $6.5 \mathrm{~km} / \mathrm{s}$ and reaches a peak value of only $7.2 \mathrm{~W} / \mathrm{cm}^{2}$ at an entry velocity of $7.0 \mathrm{~km} / \mathrm{s}$. For the 109.5 metric ton vehicle at an entry velocity of $9.1 \mathrm{~km} / \mathrm{s}$, the peak radiative heating rate reaches $171.5 \mathrm{~W} / \mathrm{cm}^{2}$, and the peak value for the 165 metric ton vehicle at an entry velocity of $9.1 \mathrm{~km} / \mathrm{s}$ increases to $241.7 \mathrm{~W} / \mathrm{cm}^{2}$.
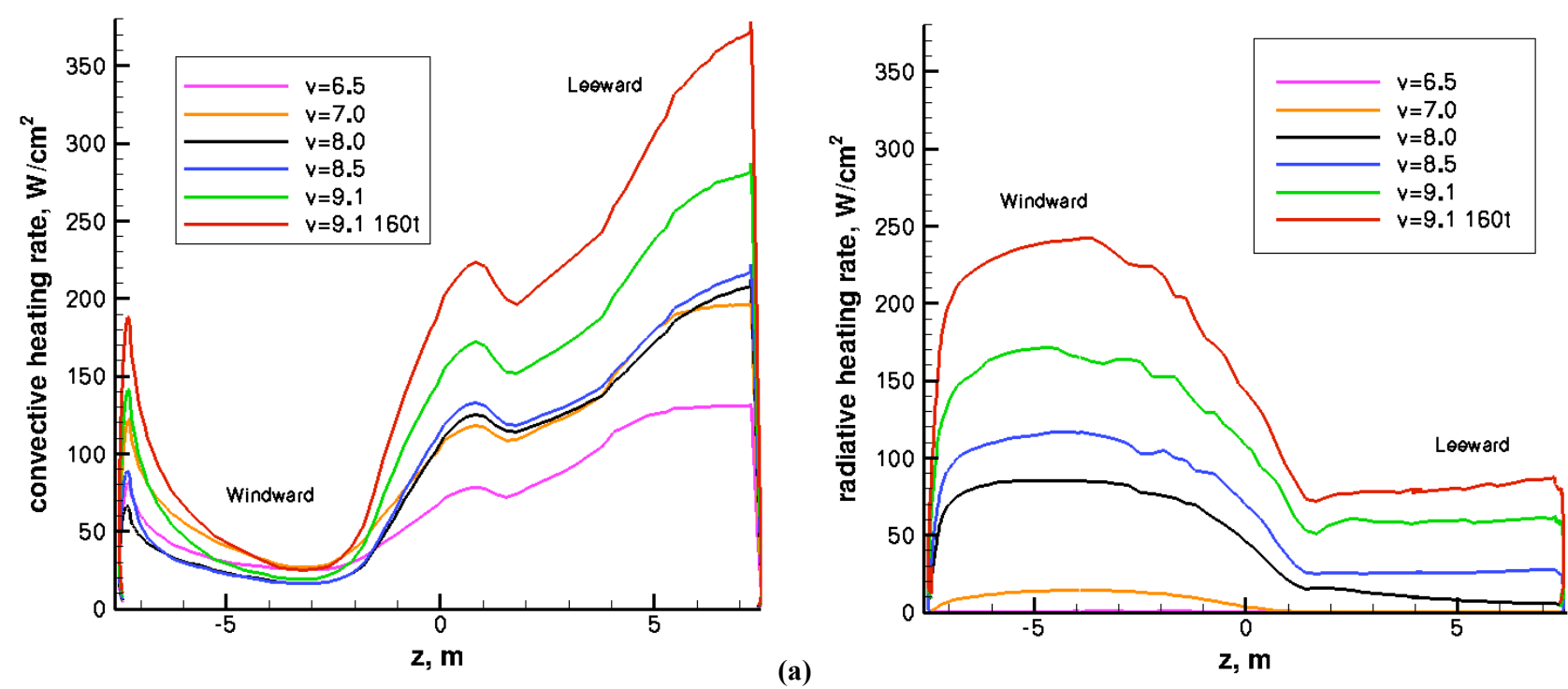

(b)

Figure 14. Centerline heating rate profiles, MSL-based vehicle. (a) convective heating. (b) radiative heating.

The centerline convective heating profiles for the Ellipsled as a function of entry velocity are shown in Fig. 15a. As was seen with the MSL-based vehicle, the lowest turbulent convective heating rate values occur at the stagnation point on the spherical part of the vehicle. The turbulent convective heating rates increase downstream of the stagnation point and reach a peak on the cylindrical part of the vehicle. For the 109.5 metric ton vehicle, the peak convective heating rate increases from 207.0 $\mathrm{W} / \mathrm{cm}^{2}$ for an entry velocity of $6.5 \mathrm{~km} / \mathrm{s}$ to $308.3 \mathrm{~W} / \mathrm{cm}^{2}$ at an entry velocity of $9.1 \mathrm{~km} / \mathrm{s}$. If the entry mass is increased to 164 metric tons, the peak convective heating rate for a $9.1 \mathrm{~km} / \mathrm{s}$ entry increases to $434.0 \mathrm{~W} / \mathrm{cm}^{2}$.

The radiative heating rate profiles on the vehicle centerline are shown in Fig. 15b. The radiative heating rate reaches a peak at the stagnation point on the hemispherical part of the vehicle, and then decreases to a fairly steady value on the cylindrical section of the vehicle. Radiative heating is minimal for the 109.5 metric ton vehicle at an entry velocity of $7.0 \mathrm{~km} / \mathrm{s}$ and increases to a peak value of $119.3 \mathrm{~W} / \mathrm{cm}^{2}$ at an entry velocity of $9.1 \mathrm{~km} / \mathrm{s}$. When the entry mass is increased to 164 metric tons, the peak radiative heating rate increases to $171.4 \mathrm{~W} / \mathrm{cm}^{2}$. Comparing results between the Ellipsled and MSL-based vehicles at the same entry velocity, the Ellipsled experiences a lower peak radiative heating rate but a higher peak turbulent convective heating rate than the MSL-based vehicle. 

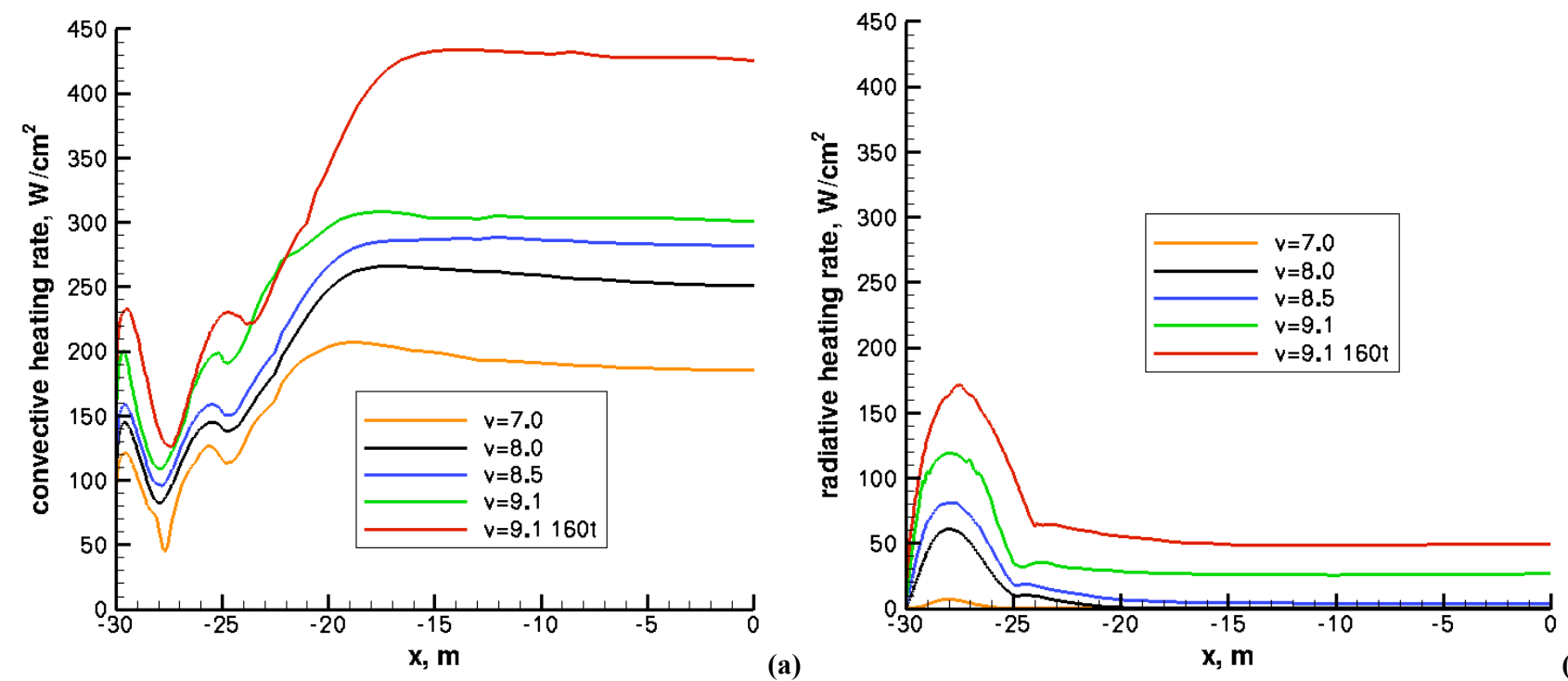

Figure 15. Centerline heating rate profiles, Ellipsled vehicle. (a) convective heating. (b) radiative heating.

The NEQAIR solutions presented in this paper so far were generated using the tangent slab approximation, where the normal LOS is extrapolated to an infinite, one-dimensional plane. Another approximation used for radiative heating calculations is known as the spherical cap approximation, where the normal LOS is mapped onto a constant radius sphere that wraps around the body. To assess the differences between the tangent slab and spherical cap results, a coupled fluids-radiation solution using the spherical cap assumption was generated over the 109.5 metric ton Ellipsled at an entry velocity of $9.1 \mathrm{~km} / \mathrm{s}$. The comparison of the radiative heating rates between the two approximations is shown in Fig. 16. The radiative heating levels are similar for the two models with the tangent slab solution being slightly conservative (gives higher radiative heating rates) compared to the spherical cap solution.

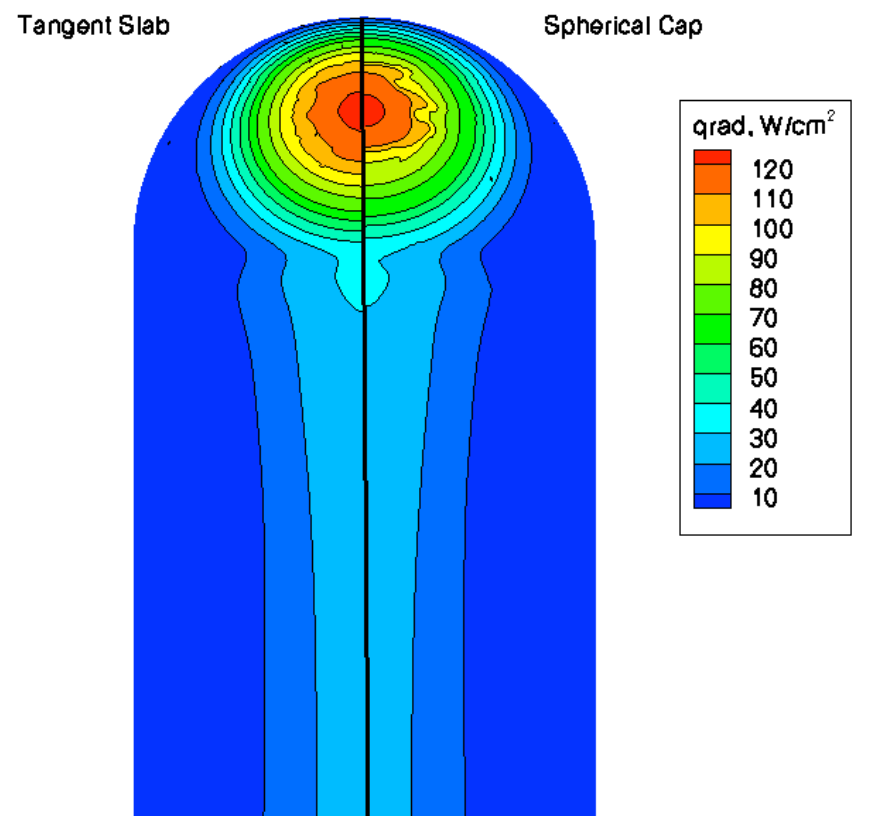

Figure 16. Comparing tangent slab and spherical cap NEQAIR solutions, $v=9.1 \mathrm{~km} / \mathrm{s}$.

\section{Concluding Remarks}

A coupled fluids-radiation analysis was performed over high-mass Mars entry vehicles using the coupled DPLR-NEQAIR code. A 70-degree sphere cone geometry based on the MSL entry vehicle and a slender, mid-L/D vehicle known as the 
Ellipsled were considered. Vehicle entry masses ranging from 102.5 to 165 metric tons and entry velocities from 6.5 to 9.1 $\mathrm{km} / \mathrm{s}$ were investigated. Radiative heating was not significant, relative to convective heating, for entry velocities below 7.0 $\mathrm{km} / \mathrm{s}$. The location of peak radiative heating was at or near the stagnation region, where the turbulent convective heating rate was the lowest. The peak turbulent convective heating occurred downstream of the stagnation point. For the same entry velocity, the Ellipsled experienced a lower peak radiative heating rate but a higher peak turbulent convective heating rate than the MSL-based vehicle. Increasing the entry mass from 100-110 metric tons to 160-165 metric tons substantially increased both the radiative and turbulent convective heating rates.

There was little effect of fluids-radiation coupling for the DPLR-NEQAIR solutions for either the MSL-based 70-degree sphere cone or Ellipsled vehicles at entry velocities below $8.0 \mathrm{~km} / \mathrm{s}$. At higher entry velocities, fluids-radiation coupling increased with a maximum reduction of surface radiative heating of $17 \%$ for the Ellipsled vehicle at an entry velocity of 9.1 $\mathrm{km} / \mathrm{s}$. There were some discrepancies between the amount of fluids-radiation coupling predicted by DPLR-NEQAIR and the Tauber-Wakefield approximation, particularly at an entry velocity of $8.0 \mathrm{~km} / \mathrm{s}$. A comparison was made between the tangent slab and spherical cap assumptions for the Ellipsled at an entry velocity of $9.1 \mathrm{~km} / \mathrm{s}$. The two models gave similar results.

\section{Acknowledgments}

This work was performed as part of the Entry, Descent, and Landing (EDL) Project within the Exploration Technology Development Program. The author was supported by contract NNA10DE12C from NASA Ames Research Center to ERC, Incorporated in support of the Thermosciences Division at NASA Ames.

\section{$\underline{\text { References }}$}

[1] Braun, R.D. and Manning, R.M., "Mars Exploration Entry, Descent, and Landing Challenges," Journal of Spacecraft and Rockets, Vol. 44, No. 2, 2007, pp. 310-323.

[2] Way, D.W., Powell, R.W., Chen, A., Steltzner, A.D., San Martin, A.M., Burkhart, P.D., and Mendeck, G.F., "Mars Science Laboratory: Entry, Descent, and Landing System Performance," IEEE Aerospace Conference Paper No. 1467, March 2006.

[3] Dwyer-Cianciolo, A.M., et al, "Entry, Descent, and Landing Systems Analysis Study: Phase 1 Report," NASA TM-2010$216720,2010$.

[4] Mars Architecture Steering Group, "Human Exploration of Mars Design Reference Architecture 5.0," NASA SP-2009$566,2009$.

[5] Steinfeldt, B.A., Theisinger, J.E., Korzun, A.M., Clark, I.G., Grant, M.J., and Braun, R.D., "High Mass Mars Entry, Descent, and Landing Architecture Assesssment," AIAA Paper 2009-6684, June 2009.

[6] Christian, J.A., Wells, G., Lafleur, J., Verges, A., and Braun, R.D., "Extension of Traditional Entry, Descent, and Landing Technologies for Human Mars Exploration," Journal of Spacecraft and Rockets, Vol. 45, No. 1, Jan. 2008, pp. 130140.

[7] Engelund, W.C., Dwyer-Cianciolo, A., Powell, R.W., Manning, R.M., Cerimele, C.J., Westhelle, C.H., Arnold, J.A., and Kinney, D.J., "Entry, Descent, and Landing Architecture and Technology Challenges for Human Exploration of Mars," Journal of Cosmology, Vol. 12, October 2010, pp. 3601-3618.

[8] Garcia, J.A., Brown, J.L, Kinney, D.J., Bowles, J.V., Huynh, L.C., Jiang, X.J., Lau, E., and Dupzyk, I.C., "CoOptimization of Mid Lift to Drag Vehicle Concepts for Mars Atmospheric Entry," AIAA Paper 2010-5052, June 2010.

[9] Wright, M.J., Candler, G.V., and Bose, D., "Data-Parallel Line Relaxation Method for the Navier-Stokes Equations," AIAA Journal, Vol. 36, No. 9, September 1998.

[10] MacCormack, R.W. and Candler, G.V, "The Solution of the Navier-Stokes Equations Using Gauss-Seidel Relaxation," Computers and Fluids, Vol. 17, No. 1, pp. 135-150.

[11] Wright, M.J., Olejniczak, J., Brown, J.L, Hornung, H.G, and Edquist, K.T., "Computational Modeling of T5 Laminar and Turbulent Heating Data on Blunt Cones, Part 2: Mars Applications,” AIAA Paper 2005-0177, January 2005. 
[12] Coblish, J.J., Smith, M.S., Hand, T., Candler, G.V., and Nompelis, I., "Double-Cone Experiment and Numerical Analysis at AEDC Hypervelocity Wind Tunnel No. 9,” AIAA Paper 2005-0902, January 2005.

[13] Wright, M.J., Milos, F.S., and Tran, P., "Afterbody Aeroheating Flight Data for Planetary Probe Thermal Protection System Design,” Journal of Spacecraft and Rockets, Vol. 43, No. 5, May 2006, pp. 929-943.

[14] MacLean, M., Holden, M., Wadhams, T., and Parker, R., "A Computational Analysis of Thermochemical Studies in the LENS Facilities,” AIAA Paper 2007-0121, January 2007.

[15] MacLean, M., Holden, M., Wadhams, T., and Parker, R., "A Computational Analysis of Thermochemical Studies in the LENS Facilities," AIAA Paper 2007-0121, January 2007.

[16] MacLean, M. and Holden, M., "Validation and Comparison of WIND and DPLR Results for Hypersonic, Laminar Problems," AIAA Paper 2004-0529, January 2004.

[17] Wright, M.J., Tang, C.Y., Edquist, K.T., Hollis, B.R., Krasa, P., and Campbell, C.A., "A Review of Aerothermal Modeling for Mars Entry Missions," AIAA Paper 2010-0443, June 2010.

[18] Edquist, K.T., Dyakonov, A.A., Wright, M.J., and Tang, C.Y., "Aerothermodynamic Design of the Mars Science Laboratory Heatshield," AIAA Paper 2009-4075, June 2009.

[19] Edquist, K.T., Dyakonov, A.A., Wright, M.J., and Tang, C.Y., "Aerothermodynamic Design of the Mars Science Laboratory Backshell and Parachute Cone," AIAA Paper 2009-4078, June 2009.

[20] Park, C., Howe, J.T., Jaffe, R.J., and Candler, G.V., "Review of Chemical-Kinetic Problems of Future NASA Missions, I: Mars Entries," Journal of Thermophysics and Heat Transfer, Vol. 8, no. 1, Jan. 1994, pp. 9-23.

[21] Baldwin, B.S. and Lomax, H., "Thin Layer Approximation and Algebraic Model for Separated Turbulent Flows," AIAA Paper 78-257, Jan. 1978.

[22] Bose, D., Wright, M.J., and Palmer, G.E., "Uncertainty Analysis of Laminar Aeroheating Predictions for Mars Entries," Journal of Thermophysics and Heat Transfer, Vol. 20, No. 4, Oct. 2006, pp. 652-662.

[23] Edquist, K.T., Dyakonov, A.A., Wright, M.J., and Tang, C.Y., "Aerothermodynamic Environments Definition for the Mars Science Laboratory Entry Capsule," AIAA Paper 2007-1206, Jan. 2007.

[24] Whiting, E.E., Park, C., Liu, Y., Arnold, J.O., and Paterson, J.A., "NEQAIR96, Nonequilibrium and Equilibrium Radiative Transport and Spectra Program: User’s Manual," NASA RP-1389, Dec. 1996.

[25] Johnston, C.O., Hollis, B.R., and Sutton, K., "Nonequilibrium Stagnation-Line Radiative Heating for Fire II," Jounral of Spacecraft and Rockets, Vol. 45, No. 6, Nov. 2008, pp. 1185-1195.

[26] Bose, D., McCorkle, E., Bogdanoff, D., and Allen, G.A., "Comparisons of Air Radiation Model with Shock Tube Measurements," AIAA Paper 2009-1030, January 2009.

[27] Cruden, B.A., Prabhu, D., Martinez, R., Le, H., Bose, D., and Grinstead, J.H., "Absolute Radiation Measurements in Venus and Mars Entry Conditions," AIAA Paper 2010-4508, June 2010.

[28] Goulard, R., "The Coupling of Radiation and Convection in Detached Shock Layers," Journal of Quantitative Spectroscopy and Radiative Heat Transer, Vol. 1, 1961, pp 249-257.

[29] Wright, M.J., Bose, D., and Olejniczak, J., "Impact of Flowfield-Radiation Coupling on Aeroheating for Titan Aerocapture," Journal of Thermophysics and Heat Transfer, Vol. 19, No. 1, Jan. 2005, pp. 17-27. 
[30] Tauber, M., and Wakefield, R., "Heating Environment and Protection During Jupiter Entry," Journal of Spacecraft and Rockets, Vol. 8, No. 3, 1971, pp 630-636.

[31] Palmer, G.E., White, T., and Pace, A., "Direct Coupling of the NEQAIR Radiation and DPLR CFD Codes," AIAA Paper 2010-5051, June 2010.

[32] Gary A. Allen, Jr., Michael J. Wright, and Peter Gage, “The Trajectory Program (Traj): Reference Manual and User's Guide", NASA TM-2004-212847, 2005.

[33] Gary A. Allen Jr., Peter J. Gage, Ethiraj Venkatapathy, David R. Olynick, and Paul F. Wercinski, "A Web-based analysis system for planetary entry vehicle design", AIAA Paper 98-4826,, Sept. 1998.

[34] Magalhaes, J.A., Schofield, J.T., and Seiff, A., "Results of the Mars Pathfinder atmospheric structure investigation", Journal of Geophysical Research, Vol. 104, No. ED4, April 1999, pp. 8943-8955.

[35] Fay, J. and Riddell, F., "Theory of Stagnation Point Heat Transfer in Dissociated Air", J. Aero. Sci, Vol. 25, No. 2, $1958, \mathrm{pp}$. 